planation for the structure of the living world, and scientists are committed to naturalistic explanations. They are willing to entertain naturalistic explanations as well as those set out by darwinians but not reference to miracles, God's plan, or guiding forces. As inadequate as sexual selection may or may not be as an explanation of the peacock's tail, it is preferable to Johnson's explanation in terms of a "whimsical Creator".

Johnson finds the commitment of scientists to totally naturalistic explanations dogmatic and close-minded, but scientists have no choice. Once they allow reference to God or miraculous forces to explain the first origin of life or the evolution of the human species, they have no way of limiting this sort of explanation. Why does the Earth have a magnetic field, why do organisms use only laevo amino acids, why is the savings and loan industry in such trouble? It is easy enough to answer that these phenomena are all part of God's great plan, but in the absence of some partially independent knowledge of God and His intentions, such explanations are no less vacuous than the usual parodies of the principle of survival of the fittest.

The compromise that scientists and theologians have hammered out through the years is that science and religion, when properly construed, cannot conflict. However, this compromise works only if neither side pushes too hard. Advocates of evolutionary ethics transgress this boundary from one side; natural theologians from the other. Advocates of evolutionary ethics claim to provide totally naturalistic explanations of ethics, whereas natural theologians acknowledge inferential relations between God and His handiwork. If the Universe is a perfectly running clock, one sort of God is implied. If, at bottom, natural processes are indeterministic and the basic regularities in the Universe are a function of the contingencies of its origin, quite another God is implied. The problem that biological evolution poses for natural theologians is the sort of God that a darwinian version of evolution implies.

What kind of God can one infer from the sort of phenomena epitomized by the species on Darwin's Galápagos Islands? The evolutionary process is rife with happenstance, contingency, incredible waste, death, pain and horror. Millions of sperm and ova are produced that never unite to form a zygote. Of the millions of zygotes that are produced, only a few ever reach maturity. On current estimates, 95 per cent of the DNA that an organism contains has no function. Certain organic systems are marvels of engineering; others are little more than contraptions. When the eggs that cuckoos lay in the nests of other birds hatch, the cuckoo chick proceeds to push the eggs of its foster parents out of the nest. The queens of a particular species of parasitic ant have only one remarkable adaptation, a serrated appendage which they use to saw off the head of the host queen. To quote Darwin, "I cannot persuade myself that a beneficent and omnipotent God would have designedly created the Ichneumonidae with the express intention of their feeding within the living bodies of caterpillars."

Whatever the God implied by evolutionary theory and the data of natural history may be like, $\mathrm{He}$ is not the Protestant God of waste not, want not. $\mathrm{He}$ is also not a loving God who cares about His productions. He is not even the awful God portrayed in the book of Job. The God of the Galápagos is careless, wasteful, indifferent, almost diabolical. He is certainly not the sort of God to whom anyone would be inclined to pray.

Johnson dedicates his book in part to "those brave souls" like himself "who

\section{Between the sheets}

\section{T. M. Hardman}

Paper Chemistry. Edited by J. C. Roberts. Blackie/Chapman and Hall: 1991. Pp.234. £59, $\$ 127.50$.

FOR anyone struggling to find a basic text on the chemistry of pulp and paper, this book will come as a great relief. It helps to provide a better understanding of what papermakers call wet-end chemistry, that is, the chemistry of the formation of paper from aqueous suspensions of cellulose fibre and other additives.

Each of the 12 chapters is written by a distinguished author in the field; most of the contributors are affiliated to industry. Two of the chapters are written to provide a background for understanding the other chapters, and it is here that some of the problems arise.

George Roberts concludes that "despite the occurrence of chain folding in cellulose single crystals, most of the available evidence is against such an arrangement in native cellulose". But the dispute over parallel versus antiparallel chain orientation in the structure of natural cellulose is not completely settled. Kurt Meyer originally proposed a model assuming parallel orientation in 1937, but later abandoned it for theoretical reasons. Martin Chang et al., in a more recent review than the references cited by George Roberts, claim that the evidence indicates that antiparallel chain orientation occurs in all cellulose crystals asked the hard questions even when there was never a chance of getting a straight answer; and to those in science who want to allow the questions to be asked." The questions that Johnson asks have been asked over and over again. Most have received very straight answers. Others are still moot. If any scientists have tried to keep these questions from being asked, they have failed miserably. Johnson's problem is that he does not like the answers that he hears. He wants evolutionary biologists to include reference to God in their professional writings in the way that he, I presume, does in his. If Johnson had written a religiously motivated criticism of thermodynamics, quantum theory or plate tectonics, it might have been worth reading, but I cannot imagine why anyone would want to read yet another rehash of creationist objections to evolutionary theory.

David L. Hull is in the Department of Philosophy, Northwestern University, Evanston, IIIinois 60208, USA.

except, perhaps, vallomic cellulose. That natural cellulose contains crystalline and amorphous regions makes the issue more difficult to resolve.

In the chapter by Tom Lindström, mention is made of how strong and weak acidic groups in sulphite pulps can be determined by conductometric titration and magnesium-elution. But no reference is made to a third way - potentiometric titration - which is referred to in Papermaking Raw Materials: Their Interaction with the Production Process and their Effect on Paper Properties (Mechanical Engineering Publications, 1985), and which is being used in the department in which I work. Furthermore, the calculation for cellulose fibres of the zeta potential by electrokinetic methods that is presented by Lindström might raise a few eyebrows, because with these methods the porosity of the fibres would lead to an underestimation.

Nevertheless, this book will have a great deal of appeal to paper scientists and technologists and it is highly recommended as a textbook for students and researchers involved in the chemistry of pulp and paper.

T. M. Hardman is in the Department of Chemistry, The University, Whiteknights, Reading RG6 $2 A D$, UK

\section{Correction}

Fundamentals of Molecular Evolution by Wen Hsiung-Li and Dan Graur and Evolution at the Molecular Level by Robert Selander, Andrew Clark and Thomas Whittam (for joint review see Nature 351, 533; 1991) are published in the United States by Sinauer and distributed elsewhere by W.H. Freeman 